\title{
LECTURAS DEL PEREGRINO JACOBEO FRANCÉS: LES CHANSONS DES PÈLERINS DE S. JACQUES
}

\author{
Ignacio Iñarrea Las Heras \\ Universidad de La Rioja
}

\begin{abstract}
RESUMEN: En este artículo se pretende mostrar cuál debía ser la forma en que los peregrinos jacobeos franceses de los siglos XVII al XIX, aproximadamente, realizaban la lectura de cierto tipo de publicaciones. Se trataba de manuales cuyo contenido fundamental estaba constituido por distintas clases de canciones populares sobre el viaje a Compostela.

La consideración de factores de naturaleza social y cultural tiene aquí una gran importancia. Sin embargo, son la temática y las finalidades de estas composiciones las que determinan cómo ha de efectuarse su adecuada comprensión. Esto se refleja claramente en las diversas formas en que el espacio jacobeo aparece representado en ellas.

RÉSUMÉ:On veut montrer dans cet article la manière dont les pèlerins français qui faisaient la route de Saint-Jacques, entre le XVIIe et le XIXe siècle, abordaient la lecture d'un certain genre de publications. C'étaient des manuels dont le contenu fondamental était constitué par plusieurs types de chansons sur le voyage à Compostelle.

La considération de facteurs sociaux et culturels est ici très importante. Cependant, ce sont surtout la thématique et les buts de ces compositions qui déterminent comment il faut les comprendre. Cela se voit clairement dans leurs diverses manières de représentation de l'espace constitué par le chemin vers la Galice.
\end{abstract}

PALABRAS CLAVE: lecturas; peregrinos; Compostela; francés; canciones.

MOTS-CLÉS: lectures; pèlerins; Compostelle; français; chansons.

La llamada littérature de colportage constituye un fenómeno cultural y editorial que se desarrolló en Francia desde el siglo XVI hasta comienzos del XX, aproximadamente $^{1}$. Como es bien sabido, se caracterizó sobre todo por su forma de difusión. Los libros que se integraban en este tipo de literatura formaban parte de la mercancía vendida por buhoneros, más o menos vagabundos, a los que se conocía

1. La littérature de colportage no existió solamente en territorio francés, sino que se desarrolló por toda Europa. Vid. Fontaine (1993) y Chartier y Lüsebrink, eds. (1996). 
con diversas denominaciones, entre ellas la de colporteurs ${ }^{2}$. Su calidad material no era muy considerable, tanto en lo que respecta a la impresión como al tipo de papel utilizado. Tal circunstancia permitía su venta a precios asequibles, sobre todo para lectores pertenecientes a clases sociales humildes. Precisamente, el público receptor de estas obras fue evolucionando a lo largo de los siglos. En un principio se componía sobre todo de burgueses dedicados a la abogacía, a la administración o al comercio, así como de terratenientes. Pero, posteriormente, se fue ampliando y diversificando, de tal manera que dio cabida (tanto en el ámbito urbano como en el rural) a una clientela más numerosa, aunque con un nivel económico mucho más modesto ${ }^{3}$. La naturaleza de estas publicaciones era realmente muy variada: los colporteurs vendían libros piadosos, de enseñanza, de magia y brujería, científicos, distintas clases de creaciones literarias (dramáticas y narrativas), canciones, periódicos conocidos como canards, etc.

Una parte muy importante de la littérature de colportage está formada por la Biblioteca Azult. Los libros que la componen se caracterizaban por el color habitualmente azul de sus tapas. Su vida editorial duró más de dos siglos (desde comienzos del XVII hasta mediados del XIX) ${ }^{5}$ y está indisolublemente vinculada

2. "Outre les livres, le colporteur proposait aussi divers petits articles -légèreté du ballot oblige!principalement de mercerie et d'images... [...] Que ce soit sous le nom de 'mercelot', 'bisouart' ou encore 'porteballes' ou 'porte paniers', le colporteur est cité dans la littérature depuis le XVème siècle." (Leclerc y Robert, 1986, vol. 1: 13). La venta ambulante de libros en Francia fue una actividad caracterizada en gran medida por la clandestinidad: "nous connaissons surtout le phénomène au travers des textes de loi tentant de régir ce commerce qui semble de plus en plus répandu mais qui est prédisposé aussi, de par sa nature même, à s'affranchir des lois et des usages." (Leclerc y Robert, 1986, vol. 1: 13). Sobre la relación entre colporteurs y editores, vid. Fontaine (1993: 69-94).

3. De todas formas, un aspecto esencial de esta evolución es el desplazamiento progresivo del público lector desde las ciudades al campo: "Essentiellement urbain au XVIIème siècle [...], le colportage de livres semble être devenu au XIXème siècle une activité principalement rurale. Il faut sans doute voir dans ce changement un effet des transformations subies par la société française: développement de l'alphabétisation dans les campagnes d'où création d'un nouveau public et donc d'un marché potentiel, mais aussi développement de la concurrence dans les villes: le colporteur ne peut subsister que là où le commerce sédentaire de librairie n'est pas présent." (Leclerc y Robert, 1986, vol. 1: 14).

4. El colportage fue, seguramente, uno de los principales medios de difusión de la Biblioteca Azul, aunque no el único: "l'importance du colportage ne doit pas faire oublier les autres moyens de diffusion des livrets bleus. Il existait aussi, en milieu urbain, une vente sédentaire qui s'effectuait par l'intermédiaire des nombreux revendeurs: ceux reconnus comme débiteurs des imprimeurs troyens dans les inventaires, les correspondants parisiens des éditeurs provinciaux, mais aussi des marchands plus occasionnels et marginaux. Ainsi est-ce une clientèle très vaste qui pouvait être touchée par ce réseau de revendeurs, sédentaires ou itinérants." (Leclerc y Robert, 1986, vol. 1: 16).

5. Vid., en relación con los orígenes y la existencia de la Biblioteca Azul, Leclerc y Robert (1986, vol. 1: 7-13) y Chartier (1987: 110-121, 247-270 у 271-351). 
a la ciudad Troyes ${ }^{6}$, ya que fue allí donde surgieron las casas de edición a las que se debió su desarrollo y esplendor?

Una manifestación concreta de la Biblioteca Azul está constituida por una serie de manuales destinados a ser utilizados por los peregrinos franceses que se dirigían hacia Compostela. En ellos se recogen pequeñas recopilaciones de canciones, oraciones dirigidas al apóstol, listas de reliquias conservadas en la catedral de Santiago, itinerarios desde Francia hasta esta ciudad y el relato (muy resumido) de la vida del santo. Asimismo, presentan ilustraciones con distintas escenas relacionadas con el mundo jacobeo (peregrinos en marcha, el milagro del ahorcado, el martirio de Santiago, etc.). El hecho de que fuesen editados preferentemente en Troyes ${ }^{8}$ lleva a pensar que esta ciudad pudo ser también un lugar de paso importante para muchos romeros ${ }^{9}$, que al llegar allí procedían a su compra:

Aussi pensons-nous que, dans tous les temps, la ville de Troyes dut servir de point de ralliement aux pélerins, qu'ils s'y assemblaient en caravane, et qu'ils s'y fournissaient de cantiques à chanter pendant le voyage. [...] Troyes offrait encore aux pélerins-voyageurs des ressources de plus d'un genre; car dès le XVIe siècle, il y avait un hôtel leur servant d'asile. [...] Enfin, l'imprimerie troyenne a fourni à ses nombreux clients plusieurs éditions d'un livret très-rare aujourd'hui. Quelques exemplaires seulement, de deux éditions différentes, sont venus jusqu'à nous [este livret es un ejemplo de esta clase de publicaciones]. (Socard, 1865: 72-73)

De todos modos, los peregrinos también podían adquirir estos libros en otros lugares de Francia, gracias precisamente a la mediación de los vendedores ambulantes, aunque también es posible que los hubiesen comprado a algún revendedor sedentario.

6. De todas formas, hubo otras ciudades en las que, siguiendo el ejemplo de Troyes, también tuvo lugar la publicación de estas obras. Fueron, sobre todo, Rouen, Caen y Limoges. Vid. Leclerc y Robert (1986, vol. 1: 8).

7. Los editores más importantes de la Biblioteca Azul fueron, sobre todo, las familias Oudot y Garnier. También son dignos de mención Jacques Sainton, A. P. F. André, y Baudot. Vid. Leclerc y Robert (1986, vol. 1: 9-11).

8. En este sentido, Camille Daux hace alusión a "ces Manuels de Cantiques, dont la fameuse Bibliothèque bleue des imprimeurs de Troyes paraît avoir été le centre." (Daux, 1899: 13). Vid. también Daux (1909: 51-53).

9. En relación con la presencia de Troyes en el entramado de rutas francesas transitadas por los peregrinos con destino a Compostela, vid. Georges (1971: 181-182), Oursel (1984: 26), La Coste-Messelière (1985: 38-39). 
Los cantos que aparecen en estos libros son sin duda su componente más importante, pues ocupan la mayor parte de sus páginas y, además, les dan título: el que, probablemente, suele aparecer con más frecuencia es Les Chansons des pèlerins de Saint Jacques. Por estos motivos, así como por tratarse de textos versificados, hecho que les da un carácter literario, van a constituir el centro de interés del presente trabajo.

Estas canciones no fueron compuestas de manera expresa para ser publicadas. Existían con anterioridad ${ }^{10}$, como parte de una tradición oral de gran antigüedad, en la cual los propios peregrinos tenían un protagonismo muy considerable, y que ha permitido la circulación y la difusión de dichas creaciones y también de todo tipo de leyendas, historias y relatos ${ }^{11}$. Una de estas composiciones, titulada La Grande Chanson des Pélerins de Saint-Jacques o Cantique Spirituel se remontaría seguramente a la época en que tuvieron lugar en Francia las Guerras de Religión. Su segunda estrofa alude, en tono de lamento, a la destrucción de iglesias por parte de los hugonotes:

Quand nous fûmes en la Saintonge,

Hélas! mon Dieu;

Nous ne trouvâmes point d'églises,

Pour prier Dieu;

Les Huguenots les ont rompues

Par leur malice,

C'est en dépit de Jésus-Christ

Et la Vierge Marie. (Daux, 1899: 23)

10. "Les cantiques ou complaintes qu'ils contiennent [estos libros para peregrinos], sous le nom de chansons, sont certainement l'oeuvre de pélerins inconnus ou de poètes populaires, plus remplis de foi que de science poétique." (Socard, 1865: 73).

"Aussi faut-il savoir gré qu'on ait eu la bonne pensée, à partir du XVIIe siècle (peut-être même antérieurement), de réunir quelques-unes de ces pièces dans des livrets, pancartes, manuels ou images à l'usage des pèlerins." (Daux, 1899: 13).

11. Esta tradición oral de esencia jacobea se remonta a la Edad Media: "Pero la Vía Compostelana es también difusora de cultura y propagadora de noticias. Gentes procedentes de Galicia refieren a los transeúntes que encuentran en su camino lo que allí han visto o las leyendas o historias que a su vez les ha contado otro caminante, compañero de viaje en alguna de las numerosas etapas del itinerario. Este aspecto queda igualmente plasmado en algunos cantares de gesta franceses, en los que el juglar pone a los peregrinos jacobeos como testigos que pueden avalar la veracidad de su relato. Así sucede con el cantar de Amis et Amile donde se nos asegura que la veracidad de la historia que se relata puede ser corroborada tanto por los clérigos como por los peregrinos que han ido a Santiago. [...] Y si no hubiera sido por aquel peregrino que procedente de Roma y de Santiago de Compostela se detiene un jueves de primavera a charlar con el clérigo Bertrand a las puertas del castillo de Bas-sur-Aube, todos nos habríamos quedado sin conocer la aventurada vida y las heroicas hazañas del conde Girart antes de que fuera señor de Viena." (Real, 1991: 22-23). 
El paso de estas composiciones a la letra impresa es sin duda un hecho de suma importancia dentro de su propia evolución, pues, aunque siguen manteniendo su naturaleza oral primitiva, van a convertirse en objeto de lectura para los peregrinos que han adquirido los libros en los que han sido recopiladas. De todas formas, como ya se ha anticipado (vid. nota 10) éstos no son el único tipo de publicación en que aparecen canciones jacobeas. También salieron a la luz durante largo tiempo estampas en las que la imagen del apóstol iba acompañada de algún canto dedicado a su figura ${ }^{12}$. Se genera así, merced a la peregrinación a Compostela (y también a otros lugares) una actividad editora y comercial de considerable intensidad ${ }^{13}$ que va a contribuir, con la intervención de los propios romeros y de los vendedores ambulantes, a la difusión de estas creaciones musicales. El texto escrito y la lectura son aquí elementos que impulsan la tradición oral:

Que si dans ces feuillets, sur ces images encadrées de prières et des cantiques en l'honneur du Saint, les pèlerins avaient les textes qu'ils allaient récitant ou chantant sur leur route, en montrant tantôt des reliques, tantôt des statuettes et autres souvenirs des sanctuaires de pèlerinage, par la vente de ces objets ils se créaient aussi des ressources pour leur voyage. Ce commerce, joint à celui que les colporteurs-imagiers faisaient au profit de leurs patrons, étendait et la renommée des lieux de dévotion et la connaissance des chants consacrés à l'honneur des saints qu'on célébrait le plus populairement. (Daux, 1899: 13)

Es importante tratar de establecer la forma en que los peregrinos hacían la lectura de estas publicaciones (libros o estampas). Más allá de su nivel social (lo más probable es que, dada la baja calidad y el precio modesto de estos artículos, sus compradores fueran sobre todo de condición más bien humilde) y cultural (en principio, se supone que los compradores de este género saben leer), hay que tener en cuenta aquí la circunstancia fundamental en la que se producía la recepción del texto escrito: el viaje. Las canciones fueron concebidas en su momento para el camino y deben ser leídas y, por supuesto, cantadas en él.

12. Vid., al respecto, Chartier (1987: 102-105).

13. "Dévotion, enthousiasme, besoin poussant les foules vers Compostelle, il fallait bien mettre à leur disposition des guides et tous autres objets utiles et pratiques. L'industrie et le commerce, devant y trouver leur avantage, secondèrent les désirs des pèlerins effectifs qui s'enrôlaient dans les Confréries de Saint-Jacques [...]. De là ces Recueils populaires au papier grossier, à l'impression défectueuse et fautive; cette Imagerie à couleurs criardes; ces Enluminures qui, peu à peu, devinrent la spécialité de certains ateliers, comme, par exemple, à Épinal; ces rudiments de Catalogues ou Itinéraires pour le parcours des chemins vers Rome, Compostelle et les Saints-Lieux; ces Manuels de Cantiques, dont la fameuse Bibliothèque bleue des imprimeurs de Troyes paraît avoir été le centre." (Daux, 1899: 13). 
Esto remite necesariamente a la noción de espacio, entendido como realidad en la que se sitúa el viajero y también como elemento de contenido de los cantos. En el primero de estos dos aspectos se puede distinguir el espacio como lugar de desplazamiento (caminos) y como lugar de descanso (albergues y hospitales). Tanto en uno como en otro, leer y cantar podría hacerse en soledad o en compañía de otros viajeros ${ }^{14}$. En este último caso, parece lógico pensar que se llevaría a cabo una forma de lectura cantada (por parte de una sola persona) que serviría de apoyo o de inicio al canto, entonado después por los demás peregrinos. Limitarse a leer y a escuchar o recitar carece de sentido, dada la naturaleza de estos textos y teniendo presente, además, que en estos libros y estampas se suele incluir al comienzo de cada canción la indicación del aire o música con la que hay que interpretarla. Así, por ejemplo, la composición titulada Chanson du devoir des Pélerins presenta, justo debajo de este título, la indicación "Sur l'air, Or sus, Peuple de France" (Anónimo, 1718: 16). Se daría, pues, una combinación de ambas actividades que se acercaría, en cierta medida, a una modalidad de lectura, de carácter más bien popular, muy practicada en Europa entre los siglos XVI al XVIII ${ }^{15}$ : la lectura en voz alta. Ésta implica, obviamente, la distinción entre el lector y el público oyente, que puede incluir a personas analfabetas o escasamente alfabetizadas: "La pratique de la lecture oralisée, décrite ou visée par les textes, crée, au moins en ville, un large public de 'lecteurs' populaires qui inclut les mal alphabétisées comme les analphabètes." (Cavallo y Chartier, 1997: 325). En tal situación, probablemente el peregrino lector empezaría entonando la primera estrofa de una canción y quienes le escuchan le contestarían con el estribillo.

14. El canto en coro era algo muy habitual, una consecuencia lógica del hecho de realizar en grupo la peregrinación a Santiago: "C'est pour des motifs différents qu'ils unissent leurs voix, ceux qui font route vers Compostelle, simples dévots, pèlerins qui sollicitent une grâce, pénitents. Peut-être ces derniers sont-ils les plus nombreux. L'habitude de se grouper entre gens d'une même paroisse, localité ou nation favorisait le chant collectif, qui était souvent un conductus paraliturgique, en latin ou en langue vulgaire." (Filgueira Valverde, 1985: 184).

"Les pèlerinages furent toujours une source d'inspiration musicale, ils influencèrent principalement le chant populaire religieux. [...] Les peuples de l'Europe qui faisaient le chemin de Saint-Jacques se mettaient en effet en route vers une terre très lointaine et quasi exotique. En de telles circonstances, le chant coule de source, surtout si le voyage se fait en groupe, ce qui est habituel maintenant et, plus encore, jadis." (López-Calo, 1985: 195).

En relación con la práctica de la lectura, colectiva e individual, en el medio urbano y en el rural, en los siglos XVI, XVII y XVIII, vid. Chartier (1987: 95-100, 238-246 y 263-265).

15. La lectura en voz alta se seguirá practicando en el siglo XIX, aunque se encontrará ya en una fase de decadencia y de retroceso frente a la lectura individual y en silencio. Vid. Lyons (1997: 399-400). 
Seguirían aquí una de las dos formas de canto por parte de los peregrinos señaladas por José Filgueira Valverde ${ }^{16}$ :

Il y aurait eu des chansons auxquelles tous participaient, sous la forme d'hymnes ou de séquences. Nous en conservons plusieurs vestiges et certaines restent actuelles. A l'occasion de ces chants, le pèlerin le plus doué pour la voix ou la mémoire entonnait les strophes, les autres lui répondant par le refrain. (1985: 184).

Nada impide creer, de todos modos, que, tras el inicio leído, todo el grupo se lanzara a cantar la canción sin establecer distinciones o que, improvisadamente, se dividiera en dos coros, de tal manera que cada uno atacara una estrofa. En este caso, serían fieles a la segunda modalidad interpretativa establecida por José Filgueira Valverde: "La distribution en deux choeurs se répondant avec des variations aurait ouvert la voie à une disposition métrique dominée par les parallélismes, les enchaînements et les refrains." (1985: 184) ${ }^{17}$.

La lectura y la interpretación de las canciones en solitario también pudieron tener lugar, en aquellas situaciones en las que el romero no tenía más remedio que hacer su viaje sin compañía. La soledad era sin duda una circunstancia determinante en la manera de vivir el viaje piadoso, especialmente en lo que se refiere a los momentos y vivencias particularmente comprometidas, difíciles o arriesgadas. Hay que tener en cuenta que la peregrinación a Santiago (o a otros centros de culto) suponía para cualquiera que la emprendiese (solo o acompañado) hacer frente a distintas clases de peligros. Podía sufrir robos, malos tratos y engaños ${ }^{18}$. También estaba expuesto a contraer enfermedades, que luego él mismo propagaba $^{19}$. La muerte por distintas causas era el último gran peligro que le acechaba y, en realidad, tenía lugar con cierta frecuencia. Los cantos que aquí nos ocupan dan cabida a estos problemas. Así se puede comprobar en Histoire arrivée à deux Pélerins, donde se cuenta cómo uno de los dos protagonistas de la narración es asesinado en un albergue a manos del posadero y de su mujer. Ambos querían quedarse con el dinero del peregrino:

16. Vid. al respecto, en relación con La Grande Chanson des Pélerins de Saint-Jacques, Villanueva (1993: 160).

17. José Filgueira Valverde señala también que cada una de estas dos formas de canto se corresponde con una determinada forma de estructurar la canción (1985: 184).

18. Vid. Vázquez de Parga, Lacarra y Uría Ríu, (1949, vol. 1: 261-262 y 266-273).

19. Vid. Vázquez de Parga, Lacarra y Uría Ríu, (1949, vol. 1: 415-421). 
Il avait quantité d'argent,

L'Hote du logis très méchant,

Comme un perfide singulier,

Sa femme étant avec lui,

Tout doucement sur le minuit,

Le Pèlerin ils égorgèrent. (Daux, 1899: 44)

No hay que olvidar problemas de índole diferente, como la posibilidad de desorientarse al llegar por primera vez a tierras desconocidas, la añoranza por el país de origen y por los seres queridos que han quedado allí, el cansancio y el hastío por lo largo y duro del camino, y también el desánimo que llevaría incluso a poner fin a la peregrinación antes de tiempo o a desistir del propósito piadoso con el que se había iniciado la ruta. Las canciones francesas tampoco ignoran tales contrariedades. Una prueba de ello se encuentra en la composición titulada Autre Chanson des Pélerins de Saint-Jacques ${ }^{20}$ :

Mais nous fûmes bien étonnés,

Quand nous fûmes à Sainte-Marie [Irún],

Là tous mes compagnons et moi

Dîmes adieu à la France jolie,

En pleurant nous nous mîmes à dire:

Adieu les nobles fleurs de lys,

En Espagne nous faut suivre;

C'est un étrange pays.

Nous avons cheminé longtemps

Dans les montagnes de Biscaye,

Cheminant toujours rudement

Par les pays en droite voie,

Jusqu'au Mont Saint-Adrien. (Daux, 1899: 39)

Podría afirmarse que la soledad hacía que se tuviera presente con mucha mayor intensidad la posibilidad de sufrir estas dificultades ${ }^{21}$. La situación de

20. Camille Daux considera que esta canción es propia de los peregrinos del norte de Francia que pasaban por París; por tal motivo la titula también canción des Parisiens. Vid Daux (1899: 38).

21. La narrativa francesa medieval ofrece algunos ejemplos de relatos milagrosos de temática jacobea, en los cuales el protagonista, un peregrino que se dirige a Compostela, se enfrenta completamente solo a situaciones de extremo peligro y de muerte. Es el caso de De celui qui se tua par l'amonestement dou dyable, contenido en Les Miracles de Nostre Dame de Gautier de Coinci o de Le Dit des .iii. pommes de Jehan de Saint-Quentin. En la primera narración, un romero se castra y se suicida por indicación engañosa del Diablo, que se le ha aparecido haciéndose pasar por el apóstol. En la segunda, otro peregrino es asesinado en un albergue del camino de Santiago, mientras su compañero de viaje pasaba la noche en otra posada. Vid. Gautier de Coinci (1966-1970, vol. 2: 237-245) y Jehan de Saint-Quentin (1978: 26-38). 
vulnerabilidad del peregrino era mucho mayor, así como su temor. Semejante disposición de ánimo tenía que ejercer necesariamente una poderosa influencia en su manera de abordar la lectura y el canto de estas composiciones. Por tal razón, las finalidades para las que fueron creadas podían ser apreciadas e interiorizadas por el peregrino con mayor claridad y profundidad. Se establecería así una especial proximidad entre la sensibilidad del viajero y los contenidos de las canciones, que podría ser considerada como una manifestación concreta del fenómeno general de la lectura silenciosa e individual ${ }^{22}$, en constante progreso a lo largo de los siglos en que la littérature de colportage y la Biblioteca Azul gozaron de la máxima vigencia.

Estas consideraciones nos llevan a establecer una identificación y clasificación de las canciones contenidas en los mencionados libros, según sus principales funciones. Hemos tomado como ejemplo representativo el manual titulado Les Chansons des pèlerins de S. Jacques ${ }^{23}$. Fue publicado en Troyes en 1718 y no

22. "Parce qu'elle annule l'écart, toujours manifeste dans la lecture à haute voix, entre le monde du texte et le monde du lecteur, parce qu'elle donne une force de persuasion inédite aux fables des textes de fiction, la lecture silencieuse [y, por, lo tanto, individual] est un enchantement dangereux." (Chartier, 1997: 324).

23. Éste es el libro al que Alexis Socard se refiere en la cita reproducida anteriormente. Todos los versos de canciones expuestos en el presente trabajo provienen de dicha obra. De todas formas, hemos preferido manejar la edición que de tales composiciones hizo Camille Daux por su mayor claridad. El propio Socard hizo una edición de las mismas con anterioridad (vid. 1865: 69-92).

Por otra parte, conviene recordar aquí que, como ha señalado Socard, no se conservan muchos ejemplares de Les Chansons des pèlerins de S. Jacques [esta situación no ha cambiado desde el siglo XIX hasta nuestros días], pero también que, en su momento, fueron muchos los peregrinos que lo adquirieron. Semejante contraste podría considerarse, siguiendo a Leclerc y Robert, como una posible demostración del éxito que debió alcanzar esta obra, interpretable de dos maneras distintas. Estos dos autores señalan, en relación con los libros de la Biblioteca Azul que se conservan actualmente: "Que représentent en effet les ouvrages que nous possédons? Sont-ce les meilleures ventes, publiées en grand nombre d'exemplaires et que, par des lois élémentares de probabilité, nous avions quelque chance de voir parvenir jusqu'à nos jours? Mais l'interprétation inverse est, elle-aussi, possible! Les ouvrages à succès sont vendus, lus et relus, et s'abîment donc rapidement, vu leur fragilité naturelle. Ils n'ont donc que bien peu de chances d'être conservés lors de déménagements ou d'héritages." (1986, vol. 1: 22).

Existen otros dos manuales muy semejantes a Les Chansons des pèlerins de S. Jacques, aunque con algunas diferencias de contenido notables. Uno de ellos se titula Chansons des Pélerins de St. Jacques. Fue publicado en Toulouse por la casa Henault, en la primera mitad del siglo XVIII, y fue objeto de una edición posterior a cargo de J.-B. Daranatz (vid. 1927, vol. 2: 23-61). El otro es La Grande Chanson des pélerins faisant le voyage de Saint-Jacques et de Rome, suivie d'autres chansons sur le même sujet et de prières choisies à l'usage des Confréries de Pélerins, publicado en el siglo XIX en Carcasona (vid. Anónimo [1862]).

Se ha preferido no tener en cuenta aquí las estampas, ya que habitualmente sólo contenían una canción sobre Santiago, que suele aparecer también en los mencionados manuales. 
presenta indicación de casa editorial. Contiene 6 cantos, además de los contenidos anteriormente indicados. Los cometidos desempeñados por estas composiciones son básicamente tres: informar y orientar, entretener y mantener viva la devoción. De este modo, se puede proponer una distribución de los textos en otros tantos grupos. La primera de las tres funciones es ejercida sobre todo por las llamadas canciones de itinerario o cantos-guía: La Grande Chanson des Pélerins de Saint-Jacques y dos textos con idéntico título Autre Chanson des Pélerins de $S$. Jacques ${ }^{24}$, si bien sus contenidos tienen claras diferencias; la segunda corresponde a la única canción narrativa existente en este manual: Histoire arrivée à deux Pélerins, antes mencionada ${ }^{25}$; la tercera concierne a las creaciones de contenido marcadamente espiritual: Chanson du devoir des Pélerins y Sur un Gentilhomme qui a fait le Voyage de S. Jacques, et s'est rendu Capucin.

La lectura, por parte del peregrino, de cada una de estas tres clases de canciones estaba predeterminada por su contenidos y finalidades, y también por lo que en cada momento necesitaba de ellas: datos objetivos concretos, distracción, consuelo y edificación moral. Por lo tanto, la manera adecuada de leer los cantos de itinerario no podía ser la misma que la que convenía al narrativo o a los espirituales. Como señala Vincent Jouve,

On ne lit pas toujours de la même façon. Comme l'ont montré les théoriciens de la lecture - et, en particulier, M. Picard -, le choix fondamental est entre la lecture "distanciée" (qui, s'intéressant aux signifiés, prend le texte comme objet d'analyse) et la lecture "participative" (qui, soumise à l'illusion référentielle, privilégie le référent). Si l'on préfère les termes de $\mathrm{B}$. Gervais l'alternative oppose la lecture "intensive" (ou "lecture-encompréhension") à la lecture "extensive" (ou "lecture-en-progression"). (1997: 181-182)

En cualquier caso, siempre debía haber una correlación entre lo que el peregrino buscaba y lo que la canción ofrecía. El lector no podía hacer más lecturas o

24. Una de estas dos canciones es la denominada des Parisiens por Camille Daux. Vid supra, nota 20.

25. Esto no significa, ni mucho menos, que no hayan existido ni circulado por la ruta jacobea, al margen de estos libros, otras canciones en las que se narraban historias diferentes. Hoy en día se conservan también textos que contienen, entre otros, el milagro del ahorcado y de las aves resucitadas o el del peregrino lanzado al mar por sus propios compañeros.

26. Vid. Picard (1986 y 1989) y Gervais (1993: 17-131). En las próximas páginas seguiremos en buena medida, en lo concerniente al estudio de las distintas formas de lectura de las canciones en relación con la noción de espacio, la metodología analítica y la terminología empleadas por Vincent Jouve (1997: 176-191). 
interpretaciones que las que la funcionalidad del propio texto le permitía. Este hecho se aprecia en el tipo de tratamiento que recibe el espacio como aspecto temático. Se podría afirmar, acerca de las canciones francesas de peregrinación que aquí nos ocupan, algo semejante a lo que señala Vincent Jouve sobre la lectura de la ficción narrativa:

La plupart des chercheurs font dépendre le régime de lecture du libre choix du sujet lisant. Il me paraît cependant que ce choix est largement programmé par le texte et, en particulier, par la façon dont l'espace est représenté. Lorsque le récit propose un espace détaillé et à forte valeur symbolique, il ralentit la progression et demande une lecture-encompréhension. Si, au contraire, il se contente de mentionner un espace stéréotypé, il appelle une compréhension fonctionnelle qui n'entrave pas la progression. (1997: 182)

Con todo, y desde otro punto de vista, no deja de tener importancia la presencia en el manual que centra aquí nuestro interés de varias ilustraciones con imágenes relacionadas con la peregrinación a Santiago. Esto permite, como indican Leclerc y Robert, una variedad de niveles de lectura que, en cualquier caso, y a pesar de su indiscutible interés, no afecta a la compresión del sentido de las canciones:

Le texte comprend un bois de titre et 10 gravures représentant des scènes de la vie de Saint Jacques ou de pèlerinage. C'est l'exemple même du texte qui autorise plusieurs niveaux de lecture, de la plus élaborée (texte seul) à la plus primaire (images seules) en passant par un niveau intermédiaire (texte-images) où l'illustration aide au déchiffrement du texte ou sert de support à l'interprétation. (1986, vol. 2: 22)

Los cantos-guía proporcionaban al peregrino de la época varias clases de datos objetivos acerca del espacio constituido por el camino de Santiago. Informaban sobre los nombres de los principales lugares por donde había que pasar. Describían brevemente localidades, regiones y parajes. Mencionaban experiencias, anécdotas y milagros. Indicaban dónde hay hospitales, albergues, santuarios de visita obligada. Advertían sobre peligros, sobre trámites de cumplimiento ineludible, etc. Son, pues, fundamentalmente, itinerarios enriquecidos con las informaciones que contienen ${ }^{27}$, como la que se ofrece en Autre Chanson des Pélerins de S. Jacques

27. "Elles [estas composiciones] fournissaient aux pèlerins futurs des données précieuses, des renseignements topographiques sur les contrées à parcourir, des indications pratiques sur les choses de nécessité ou d'utilité, telles que les provisions à faire, les objets à emporter avec soi, les dangers 
acerca del cambio de moneda que es preciso hacer en Bayona y del hecho de que en el País Vasco no se entiende a sus habitantes cuando hablan, debido sin duda a que se expresan en vasco:

Quand nous fûmes à Bayonne,

Changer fallut nos couronnes,

Nos écus et nos blancs;

C'est pour passer la Biscaye,

Où l'on n'entend point les gens. (Daux, 1899: 33)

La experiencia real es el origen de todos estos conocimientos. En la lectura que el peregrino hacía de estos textos debía predominar la dimensión cognitiva ${ }^{28}$, aunque con peculiaridades considerables con respecto a lo indicado en este sentido por Vincent Jouve (1997: 177-183). Era necesario que llevase a cabo una correcta comprensión y representación mental del espacio descrito, que luego la realidad tenía que confirmar. Pero su régimen de lectura no era participativo: al no haber narración, no puede darse la existencia de ilusión referencial. Y tampoco era plenamente distanciado, pues ofrece unos datos en cuya autenticidad era preciso creer para que estas canciones cumplieran su función orientadora: el texto no interesaba por sí mismo, sino por el referente real al que remitía.

En la Histoire arrivée à deux Pélerins la ruta de peregrinación no interesa como referente real, sino como espacio narrativo, como marco de la ficción. Aquí ya no se ofrece ningún dato informativo sobre el camino. Lo esencial del texto es el relato milagroso acerca de la amistad entre dos hombres. Al morir asesinado uno de ellos en una posada, el otro conseguirá que se haga justicia con los criminales. Después llevará el cadáver de su compañero hasta Santiago. Una vez allí, espíritu del amigo muerto se le aparecerá para agradecerle su fidelidad. La lectura de este texto presentaba, por un parte, una dimensión cognitiva en la que la representación

\footnotetext{
à éviter, les précautions à prendre, etc., etc... [...] Enfin, ce qui vaut encore mieux, ce sont les Itinéraires qu'on peut reconstituer à l'aide des divers couplets signalant les voies à prendre, les villes à voir, les particularités propres à telles localités, des épisodes qui se renouvellaient fréquemment... Par là on pouvait soit se prémunir, soit faire son profit de telles appréciations, indications, etc., etc..." (Daux, 1899: 12).

28. Vincent Jouve distingue cuatro dimensiones en el acto de la lectura: "- cognitive (la lecture est d'abord un travail de compréhension et de représentation); - affective (l'attrait de la lecture tient en grande partie aux sentiments qu'elle suscite, aux jeux d'identification qu'elle propose); - argumentative (le texte, résultat d'une volonté créatrice, ensemble organisé d'éléments, est toujours analysable comme discours, prise de position sur le monde et les êtres); - symbolique (qu'elle les récuse ou les conforte, toute lecture interagit avec les schémas dominants d'une époque)." (1997: 177). Jouve retoma aquí, en gran parte, la distinción establecida por Gilles Thérien (1990: 73-75).
} 
espacial hecha por el peregrino era forzosamente muy somera y poco detallada y, por lo tanto, estereotipada. Esto implicaba un régimen participativo que presentaba igualmente una particularidad. Hay que suponer que quien leía una canción como ésta era habitualmente una persona de fe (al menos, estaba destinada para un público creyente). Por lo tanto, el efecto que se produciría en su ánimo no sería tanto la ilusión referencial como la creencia efectiva en que la historia había tenido lugar realmente y que el milagro no era una simple leyenda.

Por otra parte, se da también aquí la existencia de una dimensión afectiva, ya que podía darse una situación de lectura que propiciaría la identificación de situaciones entre el lector y los protagonistas del relato. La definición de esta homología ${ }^{29}$ ha de estar determinada por la experiencia viajera del peregrino. Si éste nunca había ido antes a Compostela y, por lo tanto, el espacio del camino le era desconocido, se establecería entre los personajes y él una homología en el plano del significante, pero no en el plano del significado. En la canción no se menciona si los dos romeros han estado ya en Santiago y nada hace prever el crimen de los posaderos, ni mucho menos el milagro final. Pero si el lector ya había hecho este viaje anteriormente, se colocaba en una posición de sabiduría que impedía cualquier clase de identificación en el nivel del significante. Podía darse una cierta forma de homología de significado, en lo que respecta a la muerte y al robo, si había sido víctima de ladrones o si había asistido al fallecimiento (violento o no) de algún compañero de viaje.

Por último, la lectura de la Histoire arrivée à deux Pélerins tiene igualmente una dimensión argumentativa, ya que presenta una cierta organización del espacio narrativo jacobeo cargada de una significación que bien podía ser captada por el peregrino lector ${ }^{30}$. Dicha distribución espacial se basa en la oposición entre el albergue, lugar cerrado donde tiene lugar el asesinato y el robo ${ }^{31}$, y el camino,

29. "Le parallélisme entre les situations proposées par le texte et la position du lecteur peut s'appréhender sur le plan du signifiant comme sur celui du signifié. [...] Sur le plan du signifiant, il y a homologie des situations lorsque le personnage est dans la même position que le lecteur par rapport à l'univers fictionnel. Ce parallélisme dépend essentiellement de l'espace mis en scène. L'alternative, pour le texte, est la suivante: soit introduire son personnage dans un espace inconnu, soit l'ancrer dans un décor familier. [...] Sur le plan du signifié, il y a homologie des situations lorsque le personnage est confronté à une scène qui, renvoyant à des modèles archétypaux, a forcément été vécue par le lecteur." (Jouve, 1997: 184-186).

30. "S'il y a bien, de la part du lecteur, le besoin de tirer du texte une leçon, la structuration de l'espace, ne serait-ce qu'en établissant des hiérarchies et des divisions, permet de pointer l'intention du récit. [...] Nombre de récits proposent une structure spatiale explicite (haut/bas, surface/profondeur, ici/ailleurs, etc.) qui, investie sémantiquement, témoigne d'un système de valeurs." (Jouve, 1997: 187).

31. Podía existir aquí el trasfondo de la experiencia negativa de muchos peregrinos que han sufrido abusos en albergues del camino de Santiago. Vid. Vázquez de Parga, Lacarra y Uría Ríu, (1949, vol. 1: 271-273). 
espacio abierto y escenario del viaje piadoso y del buen comportamiento de los dos compañeros:

Quand ils furent sur le chemin,

L'entretien de ces Pèlerins,

Etait des paroles très saintes,

Des vies de saints par amour;

Ils s'entretenaient chaque jour,

Leurs âmes à Dieu étant sans feintes. (Daux, 1899: 44)

Esta oposición de espacios contribuye a mostrar, en última instancia, el propósito último de la canción: el elogio de la amistad entre peregrinos, así como de su devoción inquebrantable a Santiago.

La dos canciones que constituyen el tercer grupo, la Chanson du devoir des Pélerins y Sur un Gentilhomme qui a fait le Voyage de S. Jacques, et s'est rendu Capucin, no son identificables entre sí, a pesar de que en ambas se aborda la dimensión espiritual del viaje a Santiago. La primera de ellas habla de la peregrinación como experiencia real, pero da cabida de manera preferente a la exposición de lo que debe ser la actitud personal de todo aquél que se disponga a ir a Compostela. Esto queda especialmente claro en la estrofa en la que, en sentido metafórico se alude al equipaje moral del peregrino:

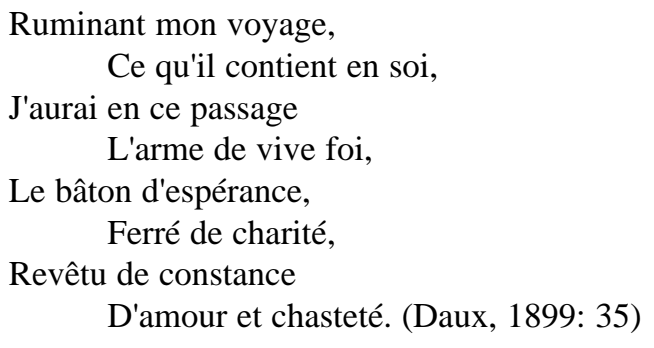

Se puede decir, por lo tanto, que en la lectura de esta canción tenía que darse una cierta forma de dimensión cognitiva. Ésta llevaría al peregrino lector a representarse el espacio del camino sobre todo como escenario de una conducta determinada. Se expone así un modelo de comportamiento idóneo, un script de obligado cumplimiento ${ }^{32}$. El régimen de lectura adecuado sería participativo y se

32. "Si la référence à l'espace facilite la représentation de l'action, c'est aussi grâce à la mise en place de scénarios prédeterminés ou 'scripts'. Les 'scripts de situation' (enchaînement de faits fondés sur le cadre) permettent cette intersection entre le monde du texte et le monde du lecteur sans laquelle il n'est pas de lecture possible. Tout cadre en effet définit un déroulement d'actions prévisible et clos, donc immédiatement reconnaissable par le lecteur." (Jouve: 1997: 179). 
basaría en creer en la validez de los contenidos expuestos. La Chanson du devoir des Pélerins es, pues, una composición con un tono claramente moralizador (el mismo título lo anticipa) ${ }^{33}$. La actuación recomendada al peregrino aparece también como una preparación (en incluso una anticipación) para la vida eterna ${ }^{34}$ :

N'appréhendons la peine

Ni le labeur aussi,

Car ce n'est chose vaine

De travailler ainsi;

Si vous désirez vivre

Au ciel heureusement,

Les peines il faut poursuivre

De votre sauvement.

De votre volonté bien sainte

Il faut servir à Dieu,

Sans aucune contrainte,

De ce terrestre lieu,

Délaissant père et mère

Et parents et amis.

Pour mériter la gloire,

Ainsi qu'il est promis. (Daux, 1899: 36)

Se aprecia aquí también una distinción de espacios, el camino jacobeo y el cielo. No se plantea entre ambos una oposición, sino una correlación, pues el primero conduce, en última instancia, al segundo. Esto determina el desarrollo de una forma de lectura argumentativa que permite al peregrino comprender la lección moral de la canción en toda su trascendencia.

Sur un Gentilhomme qui a fait le Voyage de S. Jacques, et s'est rendu Capucin tiene un rasgo que le diferencia de todas las demás canciones. La peregrinación a

33. La palabra devoir no deja lugar a dudas sobre la significación y la intención de la canción. Siguiendo a Gérard Genette, la Chanson du devoir des Pélerins pertenecería al conjunto (variado) de títulos temáticos. Se trataría, de modo más concreto, de un título literal: "Un titre thématique a donc bien des façons d'être, et chacun d'eux appelle une analyse sémantique singulière, où la part de l'interprétation du texte n'est pas mince. [...] Il y a des titres littéraux, qui désignent sans détour et sans figure le thème ou l'objet central de l'oeuvre." (Genette, 1987: 78).

34. "[Le pèlerinage à Saint-Jacques] a été ressenti par beaucoup comme une anticipation des épreuves qui attendent l'âme outre-tombe. Supporter avec constance les joies et les embûches du pèlerinage, n'est-ce pas réduire d'autant le spectre des tourments que réserve l'Au-delà? Le pèlerin qui travaille à son rachat, se prépare à affronter le jugement final dans l'espoir qu'il lui soit donné de franchir indemne le pont tendu entre les rives de la vie et de la mort." (Jacomet, 1995: 189-190). 
Compostela se presenta desde el título como ya concluida. Por lo tanto, el viaje a Santiago al que se refiere el gentilhomme en varias ocasiones a lo largo del texto no debe ser entendido en un sentido literal. Se refiere, en realidad, a su propósito de abandonar la vida mundana para ingresar en la orden franciscana y dedicarse por entero a servir a Dios. Esta idea, fundamento temático de la canción, también se anticipa de forma muy clara en el título ${ }^{35}$ e incluso se expresa directamente en una de las estrofas:

Adieu les princes et les dames,

Adieu les honneurs de la Cour,

Car je m'en vais sans plus attendre,

En un couvent finir mes jours. (Daux, 1899: 43)

Estos mismos versos muestran la forma en que la canción debía ser leída y comprendida por el peregrino. Las palabras de despedida y la indicación de adónde tiene intención de dirigirse el caballero establecen una neta distinción en el texto entre dos espacios: el siglo y el claustro. Por lo tanto, en su lectura debía predominar la dimensión argumentativa. Sin embargo, su sentido no se agota en la simple declaración de intenciones del caballero. La presencia de la metáfora del viaje a Santiago le confiere una complejidad que se plasma en una organización espacial basada en la mencionada distinción, aunque caracterizada por tener varias facetas. Ver la vida monástica como peregrinación supone concebirla como un viaje espiritual ${ }^{36}$. Esto implica establecer una oposición entre el espacio de la vida mundana, que no parece llevar a ninguna parte y al cual el caballero renuncia, y un espacio interior (correspondiente al itinerario del alma), que debe conducirle a Dios:

Adieu gentilshommes de chambre,

Tous mes laquais semblablement,

Je vous quitte sans plus attendre,

Je vais à S. Jacques le grand. (Daux, 1899: 43)

35. Sur un Gentilhomme qui a fait le Voyage de S. Jacques, et s'est rendu Capucin es también un título temático literal.

36. El concepto de peregrinación interior tiene una antigüedad considerable, pues se remonta, al menos, hasta el siglo XIV: "Dès le XIVe siècle, la tendance à l'allégorisation du pèlerinage reflète son intériorisation. On pense aux oeuvres fameuses de Guillaume de Digulleville et plus concrètement au Pèlerinage Spirituel, inspiré au chancelier Gerson (1363-1429) par le Jubilé romain de 1400." (Jacomet, 1995: 155, n. 281). 
El título de la canción anuncia ya, en sus dos partes, estos aspectos significativos. La primera de ellas, Sur un Gentilhomme qui a fait le Voyage de S. Jacques, alude a la peregrinación real a Compostela y por lo tanto, al espacio exterior, mundano. Pero también hace referencia a una etapa terminada de la vida del caballero. La segunda, et s'est rendu Capucin, muestra lo que ha sido su vida posterior y anticipa las ideas de convento y de camino interior. Además, este título muestra también una correlación entre espacios, ya que da a entender que haber transitado la ruta jacobea ha llevado al caballero a la ciudad de Santiago, pero es igualmente el motivo por el cual ha decidido hacerse religioso. Por lo tanto, se puede afirmar que en esta creación se plantean varias clases de relaciones entre el siglo y el monasterio: de oposición, de tipo causal y también temporal, pues el primero representa el pasado y el segundo el futuro (tanto terrenal como sobrenatural). En la peregrinación interior se recorre el trayecto que, tras la muerte física, permitirá acceder a un tercer y último espacio, el de la vida eterna:

Je donne toutes mes richesses

Aux pauvres tout présentement,

Afin qu'un jour avec liesse

Nous ayons part au firmament. (Daux, 1899: 43)

En el presente estudio se ha intentado mostrar que la lectura de las canciones francesas de peregrinación a Compostela contenidas en los libros mencionados y representados aquí por Les Chansons des pèlerins de S. Jacques, debía estar determinada, de una manera u otra y en mayor o menor medida, por una serie de factores de diversa naturaleza.

La pertenencia de tales manuales a la Biblioteca Azul y su vinculación con el ámbito de la venta ambulante permite suponer que estaban destinadas a un público lector de nivel social y cultural preferentemente (aunque no exclusivamente) humilde.

De modo más específico, los principales compradores serían peregrinos que se disponían a ir a Compostela (o que ya habían iniciado el viaje). Podían adquirirlo al pasar por Troyes, su lugar más habitual de edición, aunque también podrían conseguirlo en cualquier otro punto de la geografía francesa, de manos de algún colporteur o de algún comerciante sedentario.

El tránsito por la ruta jacobea y la estancia en los albergues y posadas constituyen las situaciones básicas de lectura e interpretación de las canciones. 
La temática de los textos, así como la finalidad para la que fueron creados determina muy claramente su lectura y comprensión. No hay que buscar en ellos más de lo que ofrecen: información, entretenimiento y edificación moral y espiritual. El ejercicio de estas tres funciones se puede comprobar en las formas de representación espacial que desarrollan las canciones.

En los cantos de itinerario debía predominar una lectura cognitiva y participativa que llevara a creer en la plena realidad de los datos concretos aportados sobre el camino.

La canción narrativa tenía que ser leída de tal manera que se produjese una participación, e incluso una identificación, entre el peregrino lector y el relato. Esto se produciría por medio de una lectura que habría de ser al mismo tiempo cognitiva y participativa (se daría así la total creencia en la veracidad de la historia), afectiva (se produciría una cierta forma de homología entre lector y personajes: todos son viajeros en marcha por el camino de Santiago) y argumentativa (el lector entendería el sentido último del canto).

De las dos canciones espirituales, la primera necesitaba un tipo de lectura cognitiva y participativa (es preciso creer en el valor de las normas de conducta que se proponen para transitar por la ruta jacobea) y argumentativa (también es importante captar la lección moral del texto en toda su profundidad: por el camino de Santiago también se llega a la salvación eterna). Al leer la segunda, tenía que predominar la dimensión argumentativa (de esta manera, se podría comprender la exposición de un concepto de la vida como servicio a Dios y como peregrinación interior).

De todas formas, no es fácil establecer cuál podía ser la posición subjetiva de lectura y canto por parte de los peregrinos que compraban estos manuales. Como ya se ha anticipado, no era lo mismo viajar solo que en compañía de otros romeros. Ambas situaciones determinaban seguramente actitudes distintas. En cualquier caso, hay que suponer en ellos una disposición piadosa. Por otra parte, dado que las canciones eran bastante sencillas y que esto facilitaba su lectura, audición y memorización, cabe pensar que la función de los textos escritos en que se recogían sería parecida a la de un prontuario. En este sentido, es posible que la forma más corriente de leerlas se asemejase a la que Reinhard Wittmann identifica como lecture sauvage, "à laquelle on s'adonnait d'une manière naïve, préréflexive et indisciplinée et la plupart du temps à voix haute. C'était la seule forme de lecture pour la population rurale et pour une grande partie des couches inférieures de la population citadine." (1997: 338).

Por ello, solamente la consideración de los factores expuestos (sociales, culturales y, sobre todo, textuales) constituye una base sólida para poder proponer una visión y una cierta identificación, mínimamente objetiva y fiable, del acto lector de los peregrinos en marcha hacia Compostela. 


\section{Bibliografía}

ANÓNIMO. Les Chansons des pélerins de S. Jacques. Troyes, 1718.

ANÓNIMO. La Grande Chanson des pélerins faisant le voyage de Saint-Jacques et de Rome, suivie d'autres chansons sur le même sujet et de prières choisies à l'usage des Confréries de Pélerins. Carcasona: Pierre Polère, [1862].

CHARTIER, Roger. Lectures y lecteurs dans la France d'Ancien Régime. París: Éditions du Seuil, 1987.

— "Lectures et lecteurs 'populaires' de la Renaissance à l'âge classique". En: CAVALLO, Guglielmo y Roger CHARTIER (eds.). Histoire de la lecture dans le monde occidental. París: Éditions du Seuil, 1997, p. 315-330.

- y Hans-Jürgen LÜSEBRINK (eds.). Colportage et lecture populaire: imprimés de large circulation en Europe, XVIe-XIXe siècles. París: IMEC Éditions/ Éditions de la Maison des Sciences de l'Homme, 1996.

DARANATZ, J.-B. Curiosités du Pays Basque, 2 vols. Bayona: Lasserre, 1927.

DAUX, Camille. Les Chansons des pèlerins de Saint-Jacques. Montauban: Édouard Forestié, 1899.

— Sur les chemins de Compostelle. Souvenirs historiques, anecdotiques et légendaires. Tours: Alfred Mame et Fils, 1909.

FILGUEIRA VALVERDE, José. "La littérature sur le chemin du pèlerinage de Saint-Jacques de Compostelle. Poésie et théâtre". En: Santiago de Compostela. 1000 ans de pèlerinage européen. Gante: Crédit Communal, 1985, p. 183-194.

FONTAINE, Laurence. Histoire du colportage en Europe (XVe-XIXe siècle). París: Albin Michel, 1993.

GAUTIER DE CONCI. Les Miracles de Nostre Dame. 4 vols. Ed. V. Frederic Koenig. Ginebra: Droz, 1966-1970.

GENETTE, Gérard. Seuils. París: Éditions du Seuil, 1987.

GEORGES, André. Le pèlerinage à Compostelle en Belgique et dans le Nord de la France, suivi d'une étude sur l'Iconographie de saint Jacques en Belgique. Bruselas: Palais des Académies, 1971.

GERVAIS, Bertrand. À l'écoute de la lecture. Montréal: BLV Éditeur, 1993.

JACOMET, Humbert. "Pèlerinage et culte de saint Jacques en France: bilan et perspectives". En: Pèlerinages et croisades. París: Éditions du CTHS, 1995, p. 83-200.

JEHAN DE SAINT-QUENTIN. Dits en quatrains d'alexandrins monorimes de Jehan de Saint-Quentin. Publiés par B. Munk Olsen. París: Société des Anciens Textes Français, 1978.

JOUVE, Vincent. "Espace et lecture: la fonction des lieux dans la construction du sens". En: LAVERGNE, Gérard (Ed.). Création de l'espace et narration littéraire. Nice : Université de Nice, 1997, p. 177-191. (Cahiers de narratologie; 8). 
LA COSTE-MESSELIÈRE, René de. "Voies compostellanes". En: DUPRONT, Alphonse (ed.). La Quête du sacré: Saint-Jacques de Compostelle. Turnhout: Brepols, 1985.

LECLERC, Marie-Dominique y Alain ROBERT. Des éditions au succès populaire: les livrets de la Bibliothèque Bleue, XVIIème-XIXème siècles: présentation, anthologie, catalogue. Troyes: Centre Départemental de Documentation Pédagogique, 1986.

LÓPEZ-CALO, José. "La musique sur le chemin de Saint-Jacques". En: Santiago de Compostela. 1000 ans de pèlerinage européen. Gante: Crédit Communal, 1985, p. 195-200.

LYONS, Martin. "Les nouveaux lecteurs au XIXe siècle: femmes, enfants, ouvriers". En: CAVALLO, Guglielmo y Roger CHARTIER (eds.). Histoire de la lecture dans le monde occidental. París: Éditions du Seuil, 1997, p. 365-400.

OURSEL, Raymond. Routes romanes: 2. La route aux solitudes. Saint-LégerVauban: Zodiaque, 1984.

PICARD, Michel. La Lecture comme jeu. París: Les Éditions de Minuit, 1986.

- Lire le temps. París: Les Éditions de Minuit, 1989.

REAL, Elena. "El Camino de Santiago y la epopeya francesa" Queste, 6, 1991, p. 19-29.

SOCARD, Alexis. Noëls et cantiques imprimés à Troyes depuis le XVII siècle jusqu'à nos jours. París: Auguste Aubry, 1865.

THÉRIEN, Gilles. "Pour une sémiotique de la lecture". Protée, 1990, 2-3, p. 67-80.

VÁZQUEZ DE PARGA, Luis; José Ma LACARRA y Juan URÍA RÍU. Las peregrinaciones a Santiago de Compostela, 3 vols. Madrid: Consejo Superior de Investigaciones Científicas, 1949.

VILLANUEVA, Carlos. "Música y peregrinación". En: Santiago. La Europa del peregrinaje. Barcelona: Lunwerg, 1993, p. 149-167.

WITTMANN, Reinhard. "Une révolution de la lecture à la fin du XVIII siècle?". En: CAVALLO, Guglielmo y Roger CHARTIER (eds.). Histoire de la lecture dans le monde occidental. París: Éditions du Seuil, 1997, p. 331-364. 